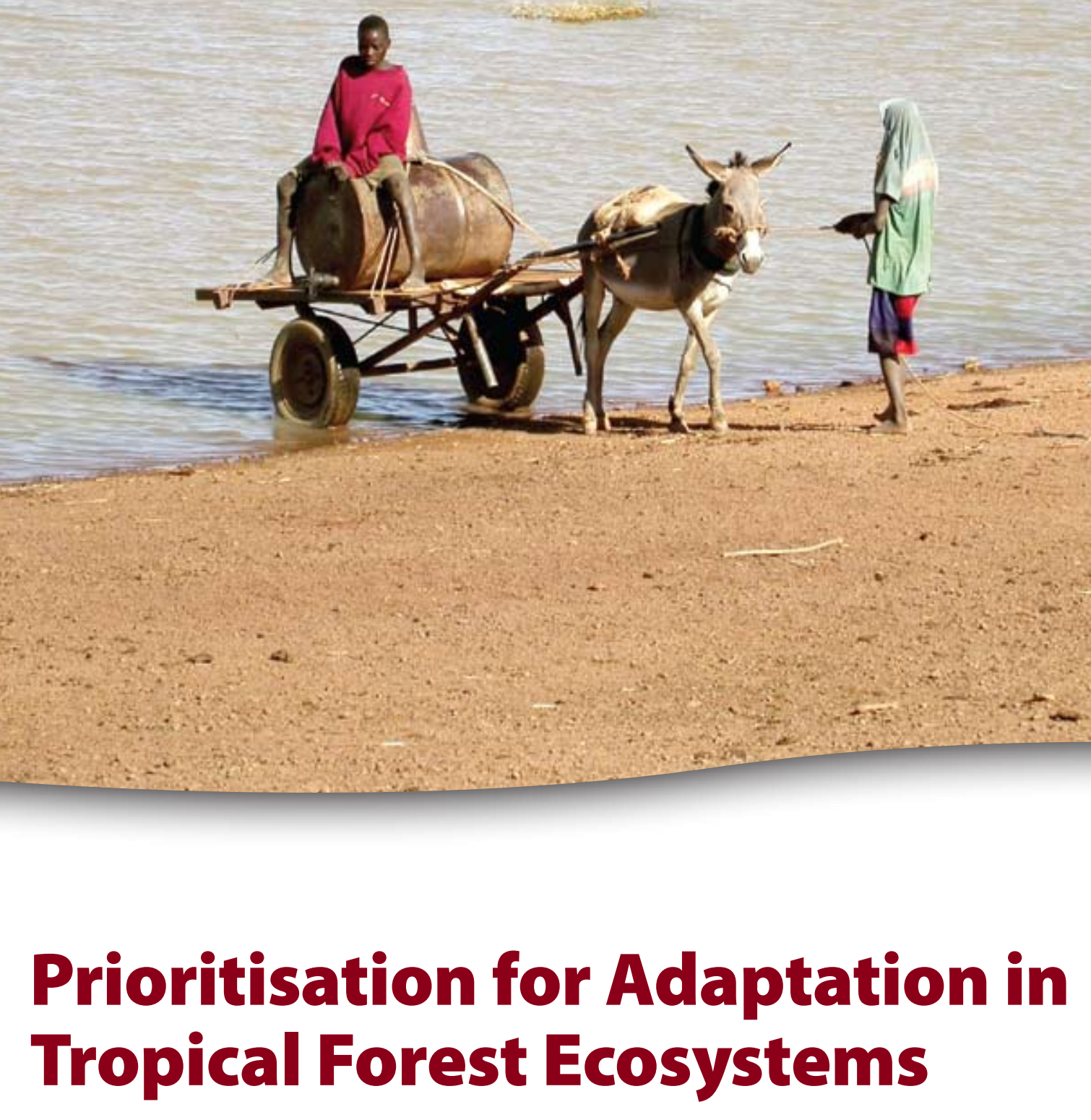

Johnson Nkem

Monica Idinoba

Heru Santoso

Carlos J. Perez

Claudio Forner

Bruno Locatelli

Markku Kanninen 

Working Paper No. 44

\section{Prioritisation for Adaptation in Tropical Forest Ecosystems}

Johnson Nkem

Monica Idinoba

Heru Santoso

Carlos J. Perez

Claudio Forner

Bruno Locatelli

Markku Kanninen

December 2008 


\section{Contact}

\section{Johnson Nkem}

Center for International Forestry Research (CIFOR)

P.O. Box 0113 BOCBD

Bogor 16000

Indonesia

Tel: +62 2518622622

Fax: +62 2518622100

Email: j.nkem@cgiar.org

Cover photo by Daniel Tiveau

\section{Acknowledgements}

The stakeholders made the project possible and their active participation gave rise to the outcomes discussed in this paper. The authors appreciate the various contributions by staff and students of the Tropical Forests and Climate Change Adaptation project.

\section{Disclaimers}

This document has been produced with the financial assistance of the European Union (EuropeAid/ENV/200481719). The contents of this document are the sole responsibility of the authors and can under no circumstances be regarded as reflecting the position of the European Union. 


\section{Abstract}

Under natural resource ecosystems shared across communities and nations, the distribution among stakeholders of risks and vulnerability to climate change is likely to be uneven on account of the nature of their stakes in the ecosystems, the degree of their dependence and the extent of degradation of the natural resources. Striving for a common adaptation strategy that safeguards the shared forest ecosystems and balances the interests of the multiple stakeholders would require a framework that encourages sharing and redistribution of ecosystem benefits and sharing of the potential climate risks and impacts on forests and stakeholders, taking into account the vulnerabilities of both ecosystems and people. This will constitute an important first step in reducing the burden of climate change on the weak and most vulnerable. Such a framework would also guide the decision making process, aid in redefining future activities especially when the risk situation changes, and help connect adaptation to sustainable national and regional development programmes through prioritisation of possible adaptation activities. This paper uses the experiences gained under the Tropical Forests and Climate Change Adaptation project of the Center for International Forest Research across three continents to propose a priority-setting process with active participation of multiple stakeholders in tropical ecosystems in developing countries perceived in their judgement to be crucial for adaptation to climate change. By attributing values to forest ecosystem goods and services for all stakeholders, prioritisation represents a common position by multiple stakeholders linking their interests and practices for a common purpose.

\section{Keywords}

Adaptation, Climate Change, Ecosystems, Priority, Vulnerability 


\section{Table of contents}

Abstract

1 Introduction

1.1 Challenging Needs for Prioritisation for Adaptation 5

1.2 Financing Adaptation 5

1.3 Linking Adaptation to National Development Goals 6

$\begin{array}{lll}1.4 & \text { Adaptation in Transboundary Natural Resources } & 7\end{array}$

2 TroFCCA Case Studies 9

2.1 TroFCCA Framework and Approach 9

2.2 Specific Activities 9

3 Results 13

4 Discussion $\quad 14$

4.1 Integration of Adaptation and National Development Goals 14

4.2 Prioritisation Framework 15

4.3 Methodological Approach $\quad 15$

5 Conclusions $r$

$\begin{array}{ll}\text { References } & 19\end{array}$ 


\section{Introduction}

$\mathbf{T}$ he severity of climate change highlighted by the Intergovernmental Panel on Climate Change's fourth assessment report (IPCC 2007) is now understood to be significantly higher than initially thought as new research findings reveal a rapidly approaching tipping point (EU Climate Change EG Science 2008; Lenton et al. 2008). This also emphasises the urgency and the enormity of the tasks in developing adequate response actions. The fourth assessment report of the IPCC (2007) also stressed the differential impacts across regions and ecosystem types with disproportionate severity on poorer nations with lower capacity to respond even in the face of urgent need for adaptation. This raises a number of ethical and equity issues that need to be addressed in any global and national climate change response actions to alleviate the burden on the most vulnerable.

In order to capture the essential needs for adaptation of the most vulnerable and stimulate collective actions it is imperative to make important choices. This is particularly crucial in natural resourcebased systems that serve as shared resources pools, where the ecosystem services that drive livelihood opportunities and national development are highly sensitive to climate change and variability. Changes in climatic patterns are generating unequivocal shifts and changes in the spatial distribution patterns of species, ecological zones, structural integrity, and biodiversity composition (Jenkins 2003; FAO 2007), which has serious implications for interactions and competition for space and resources among the constituents of the ecosystems.

Adaptation to climate change may also provide a viable route to sustainable development and go beyond mere risk minimisation and survival strategy for the poor, whose livelihood systems are increasingly exposed to extreme events (Jerneck and Olsson 2008). Since adaptation requirements are different over short, medium, and long terms, setting a framework that integrates short and long term measures for adaptation is crucial (Corfee-Morlot and Höhne 2003). Just like the global approach to climate change response under shared but differentiated responsibilities that enables the building of consensus around policies, strategies, and standards on a set of priorities, a similar approach should be used in guiding the planning and fund allocations for the implementation of adaptation at any level. This will require laying down some fundamental principles for the process to ensure fairness and equity.

Setting priority constitutes an important part of any planning process and is widely used in local and global level planning processes (Parry 2001; Cabrera et al. 2008). Although prioritisation is commonly used in scientific, policy, and development activities etc (Chan et al. 2006; Naidoo et al. 2008), motivation and methodology for prioritisation vary from one situation to the other, limit the standardisation and validation of the process across scales, and make it difficult to bring them under a standard monitoring approach. In spite of these limitations, prioritisation remains highly crucial for the adaptation processes that require funding, building consensus, partnership, and ownership among multiple stakeholders competing for the same resources diminished by climate change impacts.

\subsection{Challenging Needs for Prioritisation for Adaptation}

The complexity in climate change impacts together with other overlapping non-climatic factors is likely to complicate adaptation response measures (Burton 1996; Dovers 2008). The European Union Climate Change Expert Group (2008) recently warned that any increase in global mean temperature above $2^{\circ} \mathrm{C}$ will lead to increasingly costly adaptation. Such an increase will cause considerable impacts that surpass the adaptive capacity of many systems with a high risk of large-scale irreversible effects, and with an estimated reduction in gross domestic product of 5 to 20 percent, and even higher in the long term. The disproportionate burden of climate change impacts on developing and least developed economies needs to be addressed together with other concerns of equity in defining priorities for adaptation funding and actions (Paavola 2006). Prioritisation for adaptation has been widely emphasised (Smith 1997; Füssel and Klein 2006; FAO 2007; Huq and Ayers 2008) and encouraged in activities through the United Nations Framework Convention on Climate Change (UNFCCC) such as in the preparation of the national adaptation programme of action (NAPA) by least developed countries (LDC). However, it remains voluntary since this has not been institutionalised as a standard procedure for adaptation. This lack of mandatory provisions for adaptation is a major challenge in initiating various aspects of adaptation with the urgency that is required.

\subsection{Financing Adaptation}

The common aim of any financial investment is to achieve the intended purpose. Financing adaptation faces a fundamental challenge of reaching the ultimate target, the most vulnerable, in their adaptation needs. The global economic downturn putting a strain on funding for adaptation procurement further 
aggravates this challenge. Although no one knows the exact costs of adaptation, it is clear that the costs are going to be enormous and, therefore, financing adaptation is a major concern for Non-Annex 1 countries that are likely to bear the burden of climate change impacts without the capacity to respond. In spite of the differences in opinions in the debate on whose responsibility it is to pay for adaptation, there has been a steadily growing trend in financial pledges and contribution to the adaptation process through the global process under the UNFCCC and other multilateral agencies like the World Bank (GEF 2007; Porter et al. 2008). The Least Developed Country Fund (LDCF) and the Special Climate Change Fund (SCCF) are examples of this trend. In both these cases, the implementation rests on the Global Environmental Facility (GEF) operational guidelines 'Piloting an Operational Approach to Adaptation (SPA)' (GEF 2005, 2008), which essentially establishes strategic priorities for adaptation.

Although SPA leaned on an ecosystem approach to adaptation, the scope was primarily focused on biodiversity, climate change, land degradation, international waters, and persistent organic pollutants. Also in the case of biodiversity, the GEF (2005) placed more emphasis on integrating climate change adaptation into protected area systems rather than for multiple role forests for livelihoods and national development. The decisions of the ninth and eleventh conferences of parties, CoP9 (Decision 6/CP.9) and CoP11 (Decision 3/CP.11) provided guidelines for the operation of the LDCF to assist LDC with the implementation of their NAPAs and requested GEF to develop guidelines that ensure a cost effective, countrydriven approach in line with national priorities and creating complementarity with other funding sources, and provide for prioritisation of adaptation activities (GEF 2006).

One major outcome of CoP13, commonly referred to as the Bali Action Plans (UNFCCC 2008), is the call for enhanced action on adaptation with emphasis on the prioritisation of these actions in connection to the urgent and immediate needs of those particularly vulnerable to the impacts. The creation of the Adaptation Fund was highly welcomed by developing nations (Non-Annex 1 countries) as a global response under the UNFCCC for providing financial assistance for adaptation. One critical component of the call was for the development of eligibility criteria and priority areas. This further demonstrates the importance placed on setting priorities for adaptation. However, there is still a challenge in integrating the participation of stakeholders in the process of prioritisation for adaptation. This creates the problem of equity and justice under competition for the funds and setting priorities for adaptation funding (Tschakert 2009). Furthermore, it is unclear how and when to prioritise in order to capture the special vulnerabilities and needs of the poor in adaptation actions. And since there are no clear guidelines it is impossible to make prioritisation a precondition for the eligibility of adaptation actions or qualification of projects for public financing including accessing the Adaptation Fund.

\subsection{Linking Adaptation to National Development Goals}

Development goals presumably represent national priorities under multiple constraints of resources and capacity in undertaking a limited number of issues at a time (Stiglitz 1998). The UNFCCC calls for the stabilisation of greenhouse gas (GHG) concentrations in the atmosphere but also recognises that the parties need to take into account their specific national and regional development priorities, objectives, and circumstances that promote sustainable management (UN 1992). This requires an integrative approach that recognises national development priorities such as poverty reduction, energy supply, rural development etc (Kok et al. 2008) alongside the implementation of global goals of reduction in GHG emissions. This will also allow the integration of national actions with international actions for avoiding conflating national economic and development interests with global obligations.

A common framework for adaptation and development is vital for national implementation of both activities especially under limited resources. Mainstreaming climate change adaptation into national policies and development activities is therefore widely recommended (Klein et al. 2007; Cowling et al. 2008; Huq and Ayres 2008) especially as national development agenda and fiscal spending in many developing countries continue to be shaped by predominantly non-climatic drivers leaving behind the most vulnerable people to climate change impacts. The lack of climate change considerations in planning also weakens national ability to achieve goals like millennium development goals (MDG) 1 and 3. Following the recommendations of the Subsidiary Body for Implementation at its 25th session in Nairobi, adaptation projects should be country-driven and planned on the basis of needs, views, and priorities of eligible parties, taking into account their national sustainable development strategies, poverty reduction strategies, NAPAs, and other relevant instruments, where applicable (SBI 2006). Since the ultimate bearer of the adverse effects of climate change will be the impoverished communities, there is need for a bridging mechanism between local communities inhabiting vulnerable sites and the policy decision -making bodies that define national development goals.

Linking multiple-scale priorities and implementing similar priority across multiple scales (local, national, regional, global) that forges collective action for adaptation and development need to be addressed. 
These underlie the disconnection between national policies and local realities, and sometimes misdirect the targets of national spending of bilateral or multilateral assistances. Reconciling development goals (e.g. MDG, poverty reduction strategy) and climate change response is important for sustainable development in developing countries (Kok et al. 2008), and this requires bridging national priorities and global obligations. Even within a country, local and national priorities for adaptation need to be in sync to facilitate integration into the national development agenda especially under the consequences of economic recession on national gross domestic product and national spending.

\subsection{Adaptation in Transboundary Natural Resources}

Generally, ecosystems like forests are capital assets (Daily et al. 2000) which, under proper stewardship, yield the flow of multiple goods and services often shared by many individuals, communities, and nations. Like in most coupled systems, climate impacts on the human-environment system would produce feedbacks in the system likely to affect the flow chain of goods and services (Lamb et al. 2005; Chan et al. 2006; Tallis et al. 2008). Alterations of the patterns of natural systems by global climate change imply changes in the function and provision of ecosystem services that will require new strategies for human adaptation. This may constitute a major source of vulnerability particularly for communities dependent on these goods and services. Ecosystems are also undergoing large-scale changes through expanding human population and livelihood activities, economic growth, and changes in consumption patterns, thereby affecting both their integrity and resilience in case of disturbance (Polasky et al. 2008).

The UNFCCC requires that the stabilisation of GHG concentrations be achieved within a time frame sufficient to allow ecosystems to adapt naturally to climate change, in order to ensure that food production is not threatened and to enable economic development to proceed in a sustainable manner (UN 1992). This places emphasis on the importance of adaptation and development even while addressing mitigation, especially where natural systems drive livelihoods and national development.

Tropical forests have major roles to play in global climate change response through the multiple goods and services they provide cost-effectively to on- and off-site locations and across a wide range of people. There has been renewed attention on tropical forests for climate change response primarily for providing cost-effective options for mitigation, which is a global priority (Stern 2006). However, there are local roles of forest for livelihoods and national development. Through the multiple goods and services, tropical forests provide security portfolios for national development and for livelihoods which are also relevant for climate change response in adaptation (Newell and Stavins 1999; Kareiva et al. 2007). At the same time tropical forests are among the most complex and shared ecosystems and generally surrounded by multiple stakeholders including in transboundary situations by many nations. This increases the complexity of land use changes in developing countries as they strive for economic prosperity (Hecht and Saatchi 2007). There is always the risk of exacerbating climate change impacts across sectors and communities (Lamb et al. 2005) and influencing other climate change response actions like forestry mitigation measures such as reducing emissions from deforestation and degradation (REDD).

Transboundary resources constitute the new frontiers for the likely escalation of national conflicts in Africa for example, as climate change alters the flow of goods and services with the resultant displacement of human and wildlife in some cases. Conflicts between users of timber and non-timber forest products have been demonstrated to have implications on rural livelihoods and biodiversity conservation (Ndoye and Tiegubong 2004). All these pose additional constraints in addressing the needs of people at different scales and in various social and environmental contexts in responding to climate change.

Cohabitation is crucial under shared systems as there are multiple stakeholders and interests surrounded by institutional and tenurial rights problems (Brown and Bird 2008). Sustainability under such a framework requires the management of these multiple interests in synergies in order to maximise co-benefits and avoid cascading conflicts that could result from unmanaged synergies. Levelling the negative impacts of climate change on the local, national, and regional multiple stakeholders is crucial in managing co-existence. This would require the setting of obligations in levelling the negative impacts across scale as part of managing synergies in shared ecosystems. Thus, accurate knowledge of trade-offs and co-benefits become indispensable in forest-based climate change responses.

Smart planning is therefore essential whereby attention is paid to the most vulnerable systems and people in the process of balancing the needs of multiple stakeholders under climate crisis. Adaptation strategy that addresses the socio-economic complexity of activities and the corresponding biophysical alterations in forest ecosystems would require a consensual approach to balancing the multiple interests of stakeholders who may have intrinsic differences. Developing practical strategies for implementation therefore requires setting practical priorities that are hinged to sustainable national and regional development goals. It is also important to always recognise the disproportionate distributional impacts of climate change (Tol et al. 2004) and the differential vulnerabilities this may impinge across the multiple stakeholders (de Chazal et al. 2008). Finding 
an organised response to climate change under these complexities thus poses a major challenge. Prioritisation becomes extremely crucial in the face of these contemporary issues that are creating shifts in forest policy emphasis under global climate change. Forests also present an excellent opportunity for integrating climate change response priorities and the interface for strategically harnessing the potential for mitigation and adaptation actions that also fit into national development agenda. Through prioritisation, there is an opportunity in developing different but interconnected layers of adaptation strategies that balance the interest of multiple stakeholders while ensuring the resilience of the ecosystem and facilitating the formulation of policy. This paper highlights the importance of prioritisation for adaptation, and uses the experiences gained through CIFOR's initiatives on adaptation in tropical forests of Africa, Latin America, and Asia for demonstrating the priority-setting process in a multiple-stakeholder framework in their use of forest goods and services, and the interconnection across local, national, and regional levels. The hypothesis is that prioritisation sets the unifying platform for constituting and consolidating adaptation strategy with well balanced interests of the multiple stakeholders whereby a forwardslooking system can be firmly established among the stakeholders. This is important in guiding activities that support and complement national and regional policies and actions in responding to future climate scenarios. 


\section{TroFCCA Case Studies}

\subsection{TroFCCA Framework and Approach}

The Tropical Forests and Climate Change Adaptation (TroFCCA) project of the Center for International Forestry Research (CIFOR) is a global initiative on forests and adaptation with three regional locationsCentral America (Costa Rica, Honduras, Nicaragua), West Africa (Burkina Faso, Ghana, Mali), and South East Asia (Indonesia, the Philippines). The ultimate goal of the project is to contribute to national processes of adaptation to climate change through the assessment of vulnerability and the development of adaptation strategies, and mainstreaming these into policy.

TroFCCA uses the ecosystem approach for adaptation by planning and developing adaptation strategies using ecosystem services. The intention is to ensure that these ecosystem services, which are so important for providing livelihood opportunities for the poorer communities, remain unaffected (if not actually being enriched) by the warming climate. This provides a robust approach to adaptation that has general applicability and implications for poverty, food security, and rural energy security within the framework of sustainable development (Nkem et al. 2007). The ecosystem approach also allows for regional planning of adaptation in transboundary ecosystems shared by several nations, such as forests, river catchments, watersheds etc that constitute potential hotspots for conflicts under climate change.

Participatory approach is used throughout the life of the project and a science-policy dialogue platform has been constituted as the main vehicle for communication and planning. In line with latest developments in the science of adaptation and vulnerability, the activities of TroFCCA are focused on development issues ${ }^{1}$ of regional or national priority and ones for which forests play a substantial role. TroFCCA activities also keep adaptation connected to national development priority. The relevance of the project, therefore, lies in the scope of its analysis so that it would directly tackle vulnerability in the context of development policies.

The TroFCCA project has adopted a common methodological framework, but as a global scheme implemented across three regions and across eight countries, methodological flexibility is essential in order to capture the contextual environmental, social and economic realities in a single analysis. Thus, while the

\footnotetext{
1 Development issues may include national development objectives, policies, or broader interests linked to the process of development in a country. They may include processes for, or threats to, development related to sectors or goals for which forest goods and services play a significant role.
}

methodological framework provides top-down guidance to ensure that all regions follow the same objectives, the flexibility of the framework allows for bottom-up development of regionally specific methodologies that is incorporated in the global methodological framework.

\subsection{Specific Activities}

\section{West Africa}

There were stakeholders' consultations prior to the organisation of the regional stakeholders' kick-off meeting to introduce the project and explain the research goals and their relevance to the region and forest sectors in the different countries. A preliminary list of forests related sectors and some criteria that could be used for screening and prioritisation of the sectors were drawn up from these consultations with stakeholders. This activity was followed by a regional kick-off meeting with 65 invited stakeholders, which served to launch the project and constituted a sciencepolicy dialogue platform. The primary objective of the workshop was to identify and prioritise sectors, development topics, areas etc linked to the forest for adaptation to climate change at national and regional levels. After presentations and discussions on various aspects and forests by the various national participants, there was a guideline presented for the identification and prioritisation process. This was followed by two breakout group sessions. Participants were grouped on a country basis (Burkina Faso, Ghana, and Mali) and were asked to identify and rank all forest ecosystems sectors that were linked or relevant to their country's development agenda, particularly in addressing the needs of the poor majority. Each group nominated a session facilitator charged with guiding the group discussions and stimulating exchanges between participants by asking the right questions. The groups, after brainstorming, were supposed to decide on their scoring and ranking of the identified sectors with relevant arguments and local examples. The responses were collated and analysed by the group in making conclusions. Each group was required to make a presentation of its activities and group outcomes in the plenary session. The criteria used by each country group for scoring the sectors and arriving at the prioritised sectors were explained, and during the follow-up discussions, participants were encouraged to suggest additional criteria if applicable. Besides other countryspecific criteria, the common criteria for prioritisation included the contribution of forests ecosystems sectors to households' livelihoods, their economic importance to the population, their degree of exploitation, and their 

Table 1. Ranking forest sectors' goods and services following predefined criteria of their contribution to
livelihoods, economic importance, and perceived vulnerability

\begin{tabular}{lcccll} 
& \multicolumn{3}{c}{ Criteria (1-3) } & & \\
Sectors & $\mathbf{1}$ & $\mathbf{2}$ & $\mathbf{3}$ & Total & Goods and Services \\
Livestock fodder & 4 & 5 & 5 & 14 & Fodder resource during dry season \\
Water & 4 & 5 & 5 & 14 & Basins and rivers protection \\
Energy & 5 & 3 & 5 & 13 & Fuel wood \\
Health & 5 & 4 & 5 & 14 & Drugs for traditional medicine \\
$\begin{array}{l}\text { Biodiversity } \\
\text { conservation }\end{array}$ & 4 & 5 & 4 & 13 & Fauna and flora \\
$\begin{array}{l}\text { Human nutrition } \\
\text { Non-timber forest }\end{array}$ & 4 & 4 & 5 & 13 & Fruits, seed, beans and some tree leaves, roots, and bark \\
products & 5 & 4 & 5 & 14 & Forest products \\
$\begin{array}{l}\text { Agriculture } \\
\text { Fibres/wood }\end{array}$ & 2 & 5 & 5 & 12 & Fight against erosion, soil conservation \\
Culture & 4 & 1 & 4 & 9 & Handicraft wood, mats \\
& 3 & 1 & 3 & 7 & Habitat, rites, customs
\end{tabular}

Scores from 1 = very low to $5=$ extremely high contribution to a particular criteria

current situation, which contributes to vulnerability. Further discussions in the plenary session were used for the prioritisation of cross-country sectors as regional sectors. An illustration of the process is provided using Burkina Faso (Table 1).

\section{Burkina Faso}

Following the national priorities presented by the three countries, the cross-country sectors then turned out regional priorities following the frequency of their occurrence. The most important sectors therefore were bioenergy (fuel wood), non-timber forest products (food and medicinal plants), and water. Further verification of these selected sectors was carried out at the local level through focus group discussions and, amazingly, the sectors nominated by local communities turned out to be the same ones as those identified earlier.

\section{Central America}

For Central America, the approach was similar to that of West Africa in prioritising the sectors. A preliminary list of sectors was established following discussions among the staff. Three criteria were selected as filters for prioritising the sectors: dependence on ecosystem services provided by forests, vulnerability, and importance for national development.

Prioritisation of sectors was carried out during the regional kick-off meeting held in Costa Rica in April 2006. Following the overall objective of TroFCCA, one of the objectives of the meeting was specifically to identify and prioritise the socio-economic sectors linked to the forest for adaptation that would constitute the research focus of TroFCCA in region. There were 12 participants each from Costa Rica, Honduras, and Nicaragua, and 10 from regional institutions. Participants were from the Ministries of Environment and Natural Resources, National Offices for Climate
Change, National Offices for Disaster Prevention, and Regional or National Projects on Environmental Management and other non-governmental organisations.

The preliminary list of sectors was defined based on two United Nations classifications: the classification of activities (ISIC) and the classification of the functions of government (COFOG). A list of ecosystem services, based on the Millennium Ecosystem Assessment was also constituted. Both lists were used in building a matrix showing the links between sectors and ecosystem services, which facilitated the elimination of sectors that did not depend directly on forest ecosystem goods and services (Table 2).

Meeting participants were requested to rate vulnerability and importance of the selected sectors. The participants started with a discussion on how to evaluate vulnerability and the importance of sectors. The discussion dealt with the different dimensions of vulnerability (eg sector has been impacted by extreme weather events in the past or no alert system is available for the sector to anticipate hazards). As data were lacking for evaluating the sectors according to the different dimensions of vulnerability, participants agreed to rate the vulnerability according to their perceptions. The discussion also covered the differing understandings of the importance of a sector, in particular its economic, environmental, and social importance for sustainable development. This discussion was followed by a breakout group session on country basis (Costa Rica, Honduras, and Nicaragua). In the breakout groups, participants decided on scores for ranking the sectors according to their relevance and contribution to national development plans. Participants agreed on the three sectors that were most relevant to the three countries in Central America where the project was implemented (Table 3). 
Table 2. Sectors prioritised for their dependence on forest ecosystem services

\begin{tabular}{|ll}
\hline Sector & $\begin{array}{l}\text { Description (corresponding UN } \\
\text { classification) }\end{array}$ \\
\hline Agriculture & Crop and animal production (ISIC A01) \\
$\begin{array}{l}\text { Hunting, fishing, } \\
\text { harvesting }\end{array}$ & $\begin{array}{l}\text { Hunting, fishing and aquaculture, harvesting } \\
\text { of plants in their natural habitats, except wood } \\
\text { (adapted from ISIC 03) }\end{array}$ \\
\hline Forestry & $\begin{array}{l}\text { Forestry and logging, including harvesting of } \\
\text { wood for energy (ISIC 02) }\end{array}$ \\
$\begin{array}{l}\text { Renewable } \\
\text { energy }\end{array}$ & $\begin{array}{l}\text { Electricity production from renewable sources } \\
\text { (part of ISIC 35) }\end{array}$ \\
\hline
\end{tabular}

Tourism

Accommodation (ISIC 55), travel agency, tour operator, reservation service and related service (ISIC 79)
Drinking water Water supply (COFOG 06.3), water collection, treatment and supply (ISIC 36)
Housing Housing development (COFOG 06.1), housing and social protection (COFOR 10.6), construction of buildings (ISIC 41), real estate activities (ISIC 68)
Health Health (COFOG 07), human health activities (ISIC 86)

\section{Infrastructure Transport (COFOG 04.5), communication (COFOG 04.6), civil engineering (ISIC 42)}

$\begin{array}{ll}\text { Security } & \begin{array}{l}\text { Civil defence (COFOG 02.2), fire-protection } \\ \text { services (COFOG 03.2), public safety (COFOG } \\ \text { 03.6) }\end{array} \\ \begin{array}{l}\text { Poverty } \\ \text { reduction }\end{array} & \begin{array}{l}\text { Community development (COFOG 06.2), social } \\ \text { exclusion (COFOG 10.7), social protection } \\ \text { (COFOG 10.9) }\end{array}\end{array}$

Science

R\&D economic affairs (COFOG 04.8), R\&D environmental protection (COFOG 05.5), R\&D health (COFOG 07.5)

\section{Most relevant ecosystem services}

Provisioning services: biochemicals, food for animals

Regulating services: erosion control, water regulation and purification, pollination

Provisioning services: plants and animals

Regulating services: water regulation

Provisioning services: wood, wood energy

Provisioning services (for wood energy): wood Regulating services (for hydropower): erosion control, water regulation and purification

Provisioning services: plant, animals, and wood energy for cooking

Regulating services: water regulation and purification (for water activities) Cultural services: spiritual and religious, recreation and ecotourism, aesthetic, inspirational, cultural heritage

Regulating services: water regulation and purification

Provisioning services: wood for construction Regulating services: erosion control, water regulation (for landslides and flooding)

Provisioning services: biochemicals, food Regulating services: water purification, disease regulation

Cultural services: spiritual and religious, aesthetic, inspirational

Provisioning services: wood for construction Regulating services: erosion control, water regulation (for landslides and flooding)

Regulating services: erosion control, water regulation (for landslides and flooding)

Provisioning services: food, wood and other fibres, fuel wood, biochemicals Regulating services: erosion control, water regulation (for landslides and flooding) Cultural services: spiritual and religious, inspirational, cultural heritage

Provisioning services: biochemicals, genetic resources

\section{Table 3. Prioritised sectors}

\begin{tabular}{llll} 
Country & First prioritised sector & Second prioritised sector & Third prioritised sector \\
\hline Costa Rica & Drinking water & $\begin{array}{l}\text { Renewable energy with focus on } \\
\text { hydropower generation }\end{array}$ & $\begin{array}{l}\text { Tourism with focus on biodiversity } \\
\text { conservation and ecotourism }\end{array}$ \\
Honduras & Drinking water & $\begin{array}{l}\text { Renewable energy with focus on } \\
\text { hydropower generation }\end{array}$ & $\begin{array}{l}\text { Renewable energy with focus on } \\
\text { wood energy }\end{array}$ \\
Nicaragua & Drinking water & $\begin{array}{l}\text { Renewable energy with focus on } \\
\text { hydropower generation }\end{array}$ & $\begin{array}{l}\text { Renewable energy with focus wood } \\
\text { energy }\end{array}$
\end{tabular}




\section{Southeast Asia - Indonesia}

Prioritisation of development topics for adaptation to climate change in the forestry sector for Indonesia was conducted through consultation with the UNFCCC National Focal Point for Indonesia and a multi-stakeholder meeting. The consultation with the focal point was for scoping potential topics or issues on forestry sectors that were vulnerable to climate change. Following the findings of the consultation, a stakeholder meeting was conducted at CIFOR headquarters in Bogor, Indonesia on 29-30 May 2006. The meeting served as a means to formally introduce the project to stakeholders and potential partners in the region and to officially launch the project (kickoff meeting). A total of 30 participants representing government institutions, project implementers, academic and research organisations, international organisations, and NGOs working in the areas of forest and climate change adaptation attended the meeting. Government institutions were well represented by staff from the Ministry of Environment including the UNFCCC National Focal Point, Ministry of Forestry, National Development Planning Agency, and the Research and Development Centre of the National Agency for Meteorology and Geophysics.

The meeting objectives were to discuss needs, opportunities, and challenges in mainstreaming climate change adaptation into national development policies; to explore forests related development topics in the context of adaptation to climate change and climate variability; and to explore the contribution of TroFCCA to national processes of adaptation to climate change in Indonesia. At the same time, it provided an excellent opportunity for informative and valuable exchange of views and information among participants. Participants elaborated on the current status of adaptation work in Indonesia and the Philippines, and identified challenges in implementing adaptation, in particular, the mainstreaming of adaptation into development policies.

Participants collectively identified and agreed on the most important development issue relating to adaptation, forests, and climate change, namely, increased potential risk of forest fires and landslides. The first topic was preselected for Indonesia during consultation with the Indonesian National Focal Point and re-emphasised during the stakeholder meeting.

Forest fires are of local, national, and global relevance. They cause significant negative impacts on the environment and socio-economics. Their extent and intensity are associated with climate conditions and therefore are relevant to climate change (and climate variability). In addition, fires release large amount of $\mathrm{CO}_{2}$, a greenhouse gas that stimulates climate change. Addressing the issue of forest fires in climate change adaptation simultaneously addresses climate change mitigation.

Following the discussion during the meeting, TroFCCA in Indonesia will promote adaptation strategies to the recurrences and risks of forest fires under the influence of climate change and climate variability. Such an objective was to complement the advancement of forest fires mitigation, which was already on the government's agenda.

The second topic, increased risk of landslides, was identified during the kick-off meeting. Landslides, considered one of the most devastating natural disasters, have caused significant loss of lives and socio-economic damages in the region. The increasing number of landslides is partly due to increasing rainfall. Efforts to prevent disasters from land movements have been studied and implemented based on the prevailing climatic conditions of the last few years, and climate change is highly likely to change the characteristics of land stability. Deforestation is also thought to have an important role in landslides. Forest loss reduces root density, which provides additional cohesive strength to soil, therefore increasing the susceptibility of sloped terrain to landslides. The identification of the above issues is intended to guide the implementation of TroFCCA in Indonesia. The project activities will focus on providing policy-relevant research for mainstreaming adaptation into sectoral development policies in the context of these issues. 


\section{Results}

The principal finding was the identification and prioritisation of the development sectors for adaptation, and this occurred at two levels - national and regional (Table 4). In the three regions, all the stakeholders participating in the workshop agreed on the prioritised sectors as national and regional priorities for forestbased adaptation. Prioritisation of the sectors, areas, or topics set the stage and the agenda for the national response and for steering the implementation of the adaptation strategies. A list of partners and their potential roles in the adaptation process and in the implementation of national adaptation activities was drawn up. There was the formation of a science-policy forum in each region, which serves as a platform for coordination of adaptation to climate change activities. The prioritisation process provided the contextual placement of adaptation within the national development framework and across a landscape perspective, which provided the opportunity for regional collaborations as required for transboundary resource management.

The participatory research approach used in the prioritisation process enabled the connection of forest to national development issues by the stakeholders, and this time not through timber logging but through other forest ecosystem goods and services recognisable as important to household livelihoods and national development.

\section{Table 4. Sectors identified and prioritised by multiple stakeholders during the kick-off meetings, and the ecosystem services linked to the sectors following the Millennium Ecosystem Assessment (MEA 2005), by TroFCCA region}

\begin{tabular}{llll}
\hline Region & Prioritised sector & Ecosystem services & Type of services \\
\hline West Africa & $\begin{array}{l}\text { a. Water } \\
\text { b. Wood fuel }\end{array}$ & Fresh water & Provisioning \\
& $\begin{array}{l}\text { F. NTFP } \\
\text { - Foods }\end{array}$ & Foods & Provisioning \\
& - Medicinal & Biochemicals, natural medicines, and pharmaceuticals & Provisioning \\
Central & Water & & \\
America & - Potable water & Fresh water & Provisioning \\
& - Hydroelectricity & Fresh water & Provisioning \\
South East & Landslide & Natural hazard regulation & Regulating \\
Asia & Wildfire & Natural hazard regulation & Regulating
\end{tabular}




\section{Discussion}

Under climate change emergency it will be crucial and highly challenging to maximise returns given the multiple interests and limited resources. Decisionmaking for actions or funding allocation for adaptation will continuously be an issue facing adaptation.

To address this, there is a need for prioritisation. Prioritisation is an important step in strategising any response actions especially aimed at protecting the weak, the majority and the most vulnerable. Developing a realistic strategy for adaptation requires setting practical priorities that are linked to sustainable livelihood and national development goals. Although tropical forests remain the common ecosystem across the three global regions of TroFCCA activities, the prioritised sectors using common criteria were different across the regions (Table 4). The outcomes will likely be different if the priorities were determined outside those regions or in a global forum.

The process is an important step in galvanising support for adaptation actions from stakeholders. The achievement of a consensus among multiple stakeholders on priorities for adaptation through voluntary trade-offs of unilateral interests and positions for a common interest with the aim of achieving adaptation for all is an important milestone. The shift from stakeholders to shareholders of a common goal creates a sense of responsibility in achieving adaptation. Sharing a common interest and purpose through this process will likely reduce the risk of conflicts provoked by climate change impacts (Burton 1996) on common pool resources and transboundary situations. Prioritisation seems to allow for the redistribution of risks across different social and economic groups such that climate impacts on the forest are not too severe on the most vulnerable since their situation is reflected in the prioritisation process. A key aspect of prioritisation is the awareness that the process creates in sequencing what tasks have to be done before the other, which guides consistency, coherence, and completeness in the adaptation process. The underlying element in the adaptation activities across the three regions is their common focus on people and the community as the central issue. This demands both socio-economic adjustments and some extent of ecosystem adjustments.

TroFCCA's approach using prioritisation for adaptation demonstrates not only the issues arising from the adaptive management of forest ecological systems in the various regions, but also the challenges in undertaking sustainable development projects in economically impoverished countries. Through prioritisation the approach highlights the contextual importance of community preferences in ecosystem services as indicated by the perceptions of the stakeholders. These have major implications for adaptation planning, and also for international processes that involve forests mitigation such as REDD, since this would depend on other comparative needs of forests ecosystem services by that community. For example, is payment for carbon sequestration likely to be more important in sub-Saharan Africa than forest's other provisioning livelihood services of fresh water, wood fuel, medicinal products etc as highlighted here in this study? The contextual aspects represented in setting priorities for adaptation are crucial and should always be taken into consideration within the planning process for ecosystem services. This has the potential of giving rise to ecosystem service districts whereby countries may have local regions or districts responsible for providing a certain category of services such as flood protection or watersheds for potable water supply (Irwin and Ranganathan 2007) shared with or supplied to other regions.

From a policy perspective, the ecosystem approach of this study has provided a platform to facilitate engagement between government and local community groups, which is not always necessarily present in some of the regions. Planning the future in partnership improves the likelihood of fostering the resilience and adaptive capacity of the eco-social systems. Only time will tell, however, whether this approach is successful given weaknesses that even well-framed problems with target-driven activities can suffer, eg governance issues especially in the face of massive contextual changes and personnel turnovers in government departments common in most developing countries.

\subsection{Integration of Adaptation and National Development Goals}

The ecosystem approach of this study also provides the opportunity for integrating human and ecological priorities into development programmes that require comprehensive strategies for the utilisation of forest systems in pragmatically addressing multiple developmental goals such as environmental sustainability, poverty reduction, food, energy security, and community resilience to shocks. The approach of prioritisation provides an important synergy between national development goals and national adaptation needs from the forest which makes it attractive to policy with the add-on incentive for national budget allocation without fear of duplication of efforts under scarce resources.

The TroFCCA case studies using ecosystem approach emphasise the value placed on poverty reduction whereby the sectors prioritised for adaptation 
directly represent asset bases for the community rather than simply income sources. This is crucial for both poverty reduction (Tschakert 2007) and adaptation because it guides the formulation of policy with far reaching implications rather than just using the conventional income-based approach. UNDP (2005) considers the expansion of the asset base of the poor and raising the productivity of those assets for generating income and well-being as the way to sustainable poverty reduction. Furthermore, it emphasises the role of stakeholders in the process, which falls in the category of 'participation by consultation' as described by Walker et al. (2002). The approach, however, depends on the specific national forest policies, institutions, ownership structures, ecosystems, laws, and other national circumstances to enhance the process.

The stakeholders' science-policy dialogue platform used for the process will likely facilitate the mainstreaming of the role of forest for adaptation to climate change into national development planning. The constituted platform may also serve as an outreach outlet and for influencing the policymaking environment and the future landscape for national development processes.

The duplication of activities where resources are limited has been highlighted as one of the shortcomings in the realisation of development planning. This drives the need for the pooling of resources and knowledge for use in fully integrated planning (Ogden and Innes 2007; Sharma 2007). There are, however, barriers to achieving such synergies, some of which include institutional frameworks, political processes, information systems, and practitioner communities that have developed independently and thus remain largely separate in their systems of functioning. In contrast, the environmental services approach provides the synergy to simultaneously pursue national development goals, natural resource conservation objectives, and market opportunities for better livelihood security (Tschakert 2007 Shackleton et al. 2007).

Prioritisation for adaptation is a dynamic process that emphasises the need for monitoring and evaluation and for readjustment of priorities as update to the process after a period of time. This is important as the status of vulnerability is likely to change amongst the stakeholders prompting new priority arrangement. Prioritisation is part of the planning exercises whose effectiveness and applicability are determined, to a large extent, by integration into the planning context. This entails reconsideration of balance and relevance in the context of allocation and management of finite resources for research.

It is worthwhile to undertake the process with different types of community-driven practices as well as forest-based actors as a way of exploring their internal dynamics and external factors that limit or enable 'success', and to identify commonalities and differences embedded in different types of forest communities. This would help to identify the opportunities and limitations of transferring the experiences acquired from one community to other groups and a wider section of society.

\subsection{Prioritisation Framework}

Based on the TroFCCA experiences across three continents described above the following prioritisation framework and methodology has been developed. As an activity feeding directly into policy, the framework for prioritisation is similar to the policy framework (Walt 1996) with the aim of providing valid information for guiding actions for improvement of the well-being of the people using their risks to climate impacts. This requires participation of stakeholders (Figure 1). Their satisfaction with the outcome of the process may be a reflection of their support of the subsequent actions connected to the indigenous knowledge base of forestbased communities and the eventual policies for the overall forest communities.

\section{Figure 1. Framework for prioritisation of forest ecosystem services for adaptation planning.} (Source: Adapted from Walt 1996).

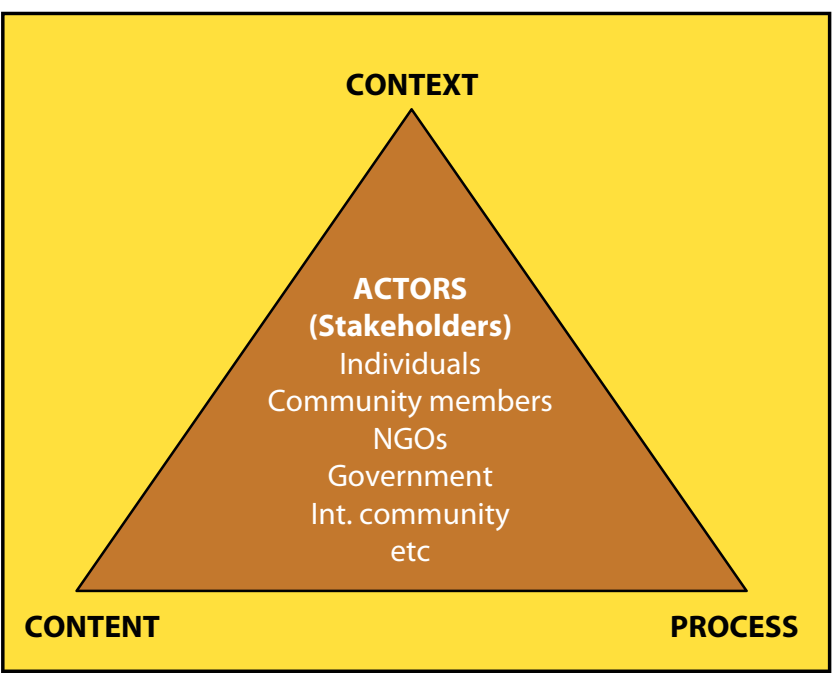

\subsection{Methodological Approach}

\section{Preparatory Work for Prioritisation}

Since no technically sound methodology is presently available for prioritisation process, a brief set of questions has been developed as an effective preparatory tool for guiding the process along.

- Who should be involved in the process and how should the group function?

- What should be the line of approach for adaptation prioritisation? 
- How much time and resource should go into the prioritisation process?

- How should one create consensus on the selection of the best methodology?

These questions are posed to a small group of professionals who can combine knowledge about the likely effects of climate change and the need for adaptation to it, about the people, terrain, natural resources, and the economy. The discussions should lead to identification and greater clarity on the following:

- Identification of problems

- Objectives of the exercise

- Defining the process

- Identification of stakeholders

- Transfer of knowledge to stakeholders on the likely effects of climate change

- Engagement of relevant stakeholders through participatory approach

- Transparent and democratic multilayered discussions

- Definition of timeframe for completion of the process

- Definition of operational modalities (national and regional).

\section{Process}

The entire process of prioritisation requires that each activity be properly documented for future reference and also for monitoring and evaluation purposes to guide future re-prioritisation processes especially in dynamic, coupled human-environment systems. The various opinions, propositions, suggestions, justifications etc are recorded in case there is need to review them in the short or long term. The process could be conducted at different levels and at both macro and micro scales. For example, it could be done at the national and regional levels but still conducted at other smaller scales (local community, departmental, or even program level).

It is important that the framework for prioritisation emphasise the process rather than the outcome. It should be conducted in a participatory approach that ensures that everyone's opinion counts. Although the prioritisation process is based on the stakeholders' perceptions, it should be driven by their personal observations and experiences, together with whatever information and supporting facts they may possess. It is crucial that the methods of consultation are transparent and logical. There should also be a built-in mechanism for monitoring and evaluating the process.

\section{Method}

The selection of an appropriate method for prioritisation that addresses the reason for the prioritisation is the most crucial part of the whole process. There are various methods leaning towards qualitative or quantitative analyses each with particular strengths and weaknesses. For a practical response to adaptation, placing too much emphasis on theoretical issues will be counter-productive to the entire process. Thus, it is important that the selected method be less complex, robust, flexible but rigorous in practice and feasible in application. Although generally, prioritisation under multiple stakeholders participatory action is a qualitative approach, it should be possible to match it quantitatively especially with forest production, climate information and scenarios in order to make projections for the future. The difficulties, however, of obtaining quantitative data in developing countries imply that there will be continuous reliance on expert judgement or opinions referred to as perception. The method selected should be subjected to sensitivity analysis if required, by changing or shifting the weights of the parameters or criteria in order to evaluate the robustness of the results of the method by simply changing the assumptions. In the case of TroFCCA study, it was accomplished through group analysis and discussion by country.

\section{Criteria}

The criteria for priority setting should be linked to human well-being in so far as it relates to forest ecosystem services and national development goals. Each stage of prioritisation may require a different set of criteria corresponding to the prevailing dynamics that reflects the context, content and process (Figure 1). Criteria should be clearly spelled out and must be independent of one another. The primary goal should be to identify criteria connecting adaptation to sustainable national and regional development and to forest management practices that ensure the flow of forest goods and services under a particular condition. The weighting given to a criterion must be an outcome of a broad consensus among stakeholders. It is also useful to develop knowledge-based criteria or non-numerical criteria, which call for human expert judgement, in addition to criteria with numerically defined weighting.

The following issues usually serve as an important input in developing criteria:

- Will the issue to be addressed have a significant impact on the present and future?

- Will the outcome of the proposed activity have a significant impact on the issue to be addressed?

- Are there sufficient capability and capacity to address the issue with confidence?

The criteria for setting priorities for adaptation should include:

- Relevance

" extent to which the effects of climate change would be alleviated

" focus on vulnerable and disadvantaged groups

" urgency

" alignment with national or global policies

- Reasons for persistence of the situation or issue e.g. climate risks such as drought 
- Knowledge available

" existing knowledge

" on-going research in the same area

" knowledge of the severity and time frame of expected impacts e.g. scenarios

" new interventions

" more cost-effective intervention(s)

" impact on national development programmes

- Feasibility

" feasibility of resources

" technical feasibility

" capacity building and available expertise

" economic feasibility

" political, social, cultural feasibility

- Ethical acceptability

From a larger global or regional perspective some other criteria may include:

- The problem of climate change is of major importance in terms of relationship to the socioeconomic development of the countries of the region.

- The solution or clarification of the problem would lead to the development or improvement of a broad national adaptation programme destined ultimately to strengthen national and/or international development involving large numbers of people.

- The adaptation activities would lead to the development of new scientific knowledge and/or adaptation strategies in various national contexts.
- The adaptation activities require regional collaborative efforts (and thus the need for a separate regional weighting of criteria) taking into account, for example, one or more of the following:

" variations in frequency and distribution of risks in different geographic areas

" difference in ecological settings that influence vulnerability to climate change and the ability to response and intervene

" opportunity to pool resources of countries in the region in addressing a common problem

" opportunity to adopt or adapt existing knowledge and technologies, including traditional systems, and to generate new knowledge if necessary, in areas directly relevant and appropriate for the socio-cultural and economic context of the problem;

- Capability to promote community participation and greater self-reliance

- Capability to improve the managerial capabilities of people and institutions at all levels of the system, including community and family

- Support for the attainment of the adaptation goal and the fostering of inter-disciplinary collaboration and multi-sectoral coordination within a country's overall development effort. 


\section{Conclusions}

Setting priority is an important step for planning adaptation actions and allocation of funding for these actions particularly because the effect of climate change will be widespread while the resources are limited. In the prioritisation process, differing interest of stakeholders, actors, and end-users are required to be balanced. The basic requirements for prioritisation are sound reasoning, competent technological and socio-economic analysis, and unbiased judgement. Prioritisation is important for engaging stakeholders, building consensus and creating a sense of ownership for adaptation actions that has the potential to guide and promote long-term sustainability. Prioritisation for adaptation is a dynamic process that needs to be regularly reviewed and updated as new knowledge emerges about the changing climate and its impacts on the forest ecosystems and the human environment. Setting priority involves identification through a consultative and analytical process that allows for both designing and securing support for actions for adaptation of these priority sectors. The process could be complex and multi-tiered, possessing both quantitative and qualitative components. However, it is better to keep it simple and built on the perception of the concerned stakeholders. Building on stakeholders' perception could also be creating a window of opportunity for advocating a change in perception and behaviour in responding to the crisis e.g. consumption or forest extraction patterns etc. The process is crucial in guiding the implementation, monitoring, and evaluation of the adaptation action. There are real opportunities in linking adaptation to national development goals through prioritisation. The establishment of regional priorities represents a set of common priorities shared by a number of countries. This is important in leveraging the actions and resources that can have large-scale effects, and for which absence of immediate action could have disastrous consequences. This is also crucial in balancing multilateral efforts for adaptation among countries with various stages of development. 


\section{References}

Brown, D. and Bird, N. 2008 The REDD road to Copenhagen: readiness for what? ODI Opinions.

Burton, I. 1996 The growth of adaptation capacity: practice and policy. In: Smith, J., Bhatti, N., Menxhulin, G., Benioff, R., Budyko, M.I., Campos, M.. Jallow, B. and Rijsbenman, F. (eds.) Adapting to climate change: An International Perspective. Springer-Verlag, New York, NY, USA, pp. 55-67.

Cabrera, D., Mandel, J.T., Andras, J.P. and Nydam, M.L. 2008 What is the crisis? Defining and prioritizing the world's most pressing problems. Frontiers of Ecology and Environment 6(9): 469-475.

Chan, K.M.A., Shaw, M.R., Cameron, D.R., Underwood, E.C. and Daily, G.C. 2006 Conservation planning for ecosystem services. PLoS Biology 4(11): e379. DOI: 10.1371/journal.pbio.0040379.

Corfee-Morlot, J. and Höhne, N. 2003 Climate change: long-term targets and short-term commitments. Global Environmental Change 13: 277-293.

Cowling, R.M., Egoh, B., Knight, A.T., O’Farrell, P.J., Reyers, B., Rouget, M., Roux, D.J., Welz, A. and Wilhelm-Rechman, A. 2008 An operational model for mainstreaming ecosystem services for implementation. Proceedings of the National Academy of Science of the United States of America 105(28): 9483-9488.

Daily, G.C. et al. 2000 The value of nature and the nature of value. Science 289(5478): 395-396.

de Chazal, J., Quetier, F., Lavorel, S. and Doorn, A.V. 2008 Including multiple differing stakeholder values into vulnerability assessments of socioecological systems. Global Environmental Change, doi:10.1016/j. gloenvcha.2008.04.005.

Dovers, S. 2008 Normalizing adaptation. Global Environmental Change doi:10.1016/j. gloenvcha.2008.06.006.

EU Climate Change EG Science 2008 The $2^{\circ} \mathrm{C}$ target information reference document: background on impacts, emission pathways, mitigation options and cost. Version 9.1.

FAO 2007 Adaptation to climate change in agriculture, forestry and fisheries: perspective, framework and priorities. Food and Agriculture Organization of the United Nations, Rome, Italy.

Füssel, M. and Klein, R.J. 2006 Climate change vulnerability assessments: an evolution of conceptual thinking. Climate Change 75: 301-329.

GEF 2005 Operational guidelines for the strategic priority: piloting an operational approach to adaptation (SPA). GEF/C.27/Info.10. Global Environmental Facility, Washington, DC.
GEF 2006 Programming paper for funding the implementation of the NAPAs under LDC Trust Fund. GEF/C.28/18. Global Environmental Facility, Washington, DC.

GEF 2007 Financing adaptation action. Global Environmental Facility, Washington, DC.

GEF 2008. Report on the completion of the strategic priority on adaptation. GEF/C.34/8. GEF Council, Agenda Item 13.

Hecht, S.B. and Saatchi, S. S. 2007 Globalisation and forest resurgence: changes in forest cover in El Salvador. BioScience 57(8): 663-672.

Huq, S. and Ayers, J. 2008 Streamlining adaptation to climate change into development projects at the national and local level. In: Financing climate change policies in developing countries. European Parliament, Brussels.

IPCC, 2007. Fourth assessment report. Impacts, Adaptation and Vulnerability. Contribution of Working Group II to the Fourth Assessment Report of the Intergovernmental Panel on Climate Change, Cambridge University Press.

Irwin, F. and Ranganathan, J. 2007 Restoring nature's capital: an action agenda to sustain ecosystem services. World Resources Institute, Washington, D.C.

Jenkins, M. 2003 Prospects for biodiversity. Science 302: 1175-1177.

Jerneck, A. and Olsson, L. 2008 Adaptation and the poor: development, resilience and transition. Climate Policy 8(2): 170-182.

Kareiva, P., Watts, S., McDonald, R. and Boucher1, R. 2007 Domesticated Nature: Shaping landscapes and ecosystems for human welfare. Science 316: 1866-1869.

Klein, R.J.T., Eriksen, S.E.H., Naess, L.O., Hammill, A., Tanner, T.M., Robledo, C. and O'Brien, K.L. 2007 Portfolio screening to support the mainstreaming of adaptation to climate change into development. Climate Change 84(1): 23-44.

Kok, M., Metz, B., Verhagen, J. and Van Rooijen, S. 2008 Integrating development and climate policies: national and international benefits. Climate Policy 8(2): 103118.

Lamb, D., Erskine, P.D. and Parrotta, J.A. 2005 Restoration of degraded tropical forest landscapes. Science 310: 1628-1632.

Lenton, T.M., Held, H., Kriegler, E., Hall, J.W., Lucht, W., Rahmstorf, S. and Schellnhuber, H.J. 2008 Tipping elements in the earth's climate system. Proceedings of the National Academy of Science of the United States of America 105(6): 1786-1793. 
Millennium Ecosystem Assessment (MEA) 2005 Ecosystems and human well-being: synthesis. Island Press, Washington, DC.

Naidoo, R., Balmford, A., Costanza, R., Fisher, B., Green, R.E., Lehner, B., Malcolm, T.R. \& Ricketts, T.H. 2008 Global mapping of ecosystem services and conservation priorities. Proceedings of the National Academy of Science of the United States of America 105(28): 9495-9500.

Ndoye, O. and Tiegubong, J.C. 2004 Forest resources and rural livelihoods: the conflict between timber and nontimber forest products in the Congo basin. Scandinavian Journal of Forest Research 19(4): 36-44.

Newell, R.G. and Stavins, R.N. 1999 Climate change and forest sinks: factors affecting the costs of carbon sequestration. RFF Discussion Paper 99-31 REV.

Nkem, J., Santoso, H., Murdiyarso, D., Brockhaus, M. and Kanninen, M. 2007 Using tropical forest ecosystem goods and services for planning climate change adaptation with implications for food security and poverty reduction. Journal of Semi-Arid Tropical Agricultural Research 4(1): 1-23.

Ogden, A.E. and Innes, J. 2007 Incorporating climate change adaptation considerations into forest management planning in the boreal forest. International Forestry Review 9(3): 713-733.

Paavola, J. 2006 Justice in adaptation to climate change in Tanzania. In: Adger, W.N., Paavola, J., Huq, S. and Mace, M.J. (eds.) Fairness in adaptation to climate change, 201-222. The MIT Press, Cambridge, Massachusetts.

Parry, M., 2001. Climate change: where should our research priorities be? Global Environmental Change 11: $257-$ 260.

Polasky, S. et al. 2008 Where to put things? Spatial land management to sustain biodiversity and economic returns. Biological Conservation 141(6): 1505-1524.

Porter, G., Bird, N., Kaur, N. and Peskett, L. 2008 New finance for climate change and the environment. The Heinrich Boll Foundation and WWF.

SBI 2006 Report of the Subsidiary Body for Implementation on its twenty-fifth session, held at Nairobi, Kenya, 6 - 14 November 2006. UNFCCC/SBI/2006/28

Shackleton, S., Shanley, P. and Ndoye, O. 2007 Invisible but viable: recognizing local markets for non-timber forest products. International Forestry Review 9(3): 697-712.
Sharma, A. 2007 Assessing, predicting and managing current and future climate variability and extreme events, and implications for sustainable development. Background paper commissioned by UNFCCC workshop on climate related risks and extreme events under the Nairobi work programme on impacts, vulnerability and adaptation, Cairo, Egypt, 18-20 June 2007.

Smith, J.B. 1997 Setting priorities for adapting to climate. Global Environmental Change 7(3): 251-264.

Stern, N. 2006 The economics of climate change: the Stern review. Cambridge University Press, Cambridge.

Stiglitz, J.E. 1998 Towards a new paradigm for development: strategies, policies, and processes. Prebisch Lecture, 19 October 1998.

Tallis, H., Kareiva, P., Marvier, M. and Chang, A. 2008 An ecosystem services framework to support practical conservation and economic development. Proceedings of the National Academy of Science of the United States of America 105(28): 9457-9464.

Tol, R.S.J., Downing, T.E., Kuik, O.J. and Smith, J.B. 2004 Distributional aspects of climate change impacts. Global Environmental Change 14(3): 259-272.

Tschakert P. 2007 Environmental services and poverty reduction: options for smallholders in the Sahel. Agricultural Systems 94(1): 75-86.

Tschakert, P. 2009 Ethics in adaptation decision-making: learning tools and tipping points. http://climateethics. $\operatorname{org} / \mathrm{p}=60$.

UNDP 2005 Investing in environmental wealth for poverty reduction. United Nations Development Programme, New York.

UNFCCC 2008 Report of the conference of the parties on its thirteenth session, held in Bali from 3 to 15 December 2007. FCCC/CP/2007/6/Add.1.

United Nations 1992 UN Framework Convention on Climate Change (United Nations, Climate Change Secretariat, Palais des Nations, Geneva.

Walker, B., Carpenter, S., Anderies, J., Abel, N., Cumming, G.S., Janssen, M., Lebel, L., Norberg, J., Peterson, G.D. and Pritchard, R. 2002 Resilience management in social-ecological systems: a working hypothesis for a participatory approach. Conservation Ecology 6(1): 14. http://www.consecol.org/vol6/iss1/art14.

Walt, G. 1996 Policy analysis: an approach. In: Janovsky, K. (ed.) Health policy and systems development, 227. World Health Organization, Geneva. 



\section{Center for International Forestry Research (CIFOR)}

CIFOR advances human wellbeing, environmental conservation, and equity by conducting research to inform policies and practices that affect forests in developing countries. CIFOR is one of 15 centres within the Consultative Group on International Agricultural Research (CGIAR). CIFOR's headquarters are in Bogor, Indonesia. It also has offices in Asia, Africa and South America. CIFOR works in over 30 countries worldwide and has links with researchers in 50 international, regional and national organisations.

To request a copy of this publication, please contact cifor@cgiar.org

\section{www.cifor.cgiar.org}

